\title{
Spontaneous Intracranial Hypotension - MRI Features
}

\author{
Krishna Kumar $\mathbf{M}^{1 *}$, Kumaran $\mathbf{R}^{2}$ and Yogaraj $\mathrm{S}^{2}$ \\ ${ }^{1}$ Associate Professor of Radiodiagnosis, Velammal Medical College \& Research Institute, India \\ ${ }^{2}$ Assistant Professor of Radiodiagnosis, Velammal Medical College \& Research Institute, India
}

Submission: June 03, 2017; Published: July 24, 2017

*Corresponding author: Krishna Kumar M, Associate Professor of Radiodiagnosis, Velammal Medical College \& Research Institute, Velammal Village, Tuticorin Ring Road, Anuppanadi, Madurai, Tamilnadu-625009, India, Tel: +919447345528; Email: drmkrishnakumar@gmail.com

\begin{abstract}
Spontaneous intracranial hypotension (SIH) is being recognized with increasing frequency with magnetic resonance imaging (MRI). Orthostatic headache, low CSF pressure, and diffuse meningeal enhancement on brain MRI are the major features of the classic syndrome. Low pressure headaches are caused by low cerebral spinal fluid (CSF) pressure or volume, and they may be spontaneous or provoked (for example, after lumbar puncture, inadvertent dural puncture during spinal anesthesia or neurosurgical procedures). Low pressure headache without apparent provocation is termed SIH. Such headaches are typically postural they are eased by lying down but worsened in the upright position, which may result in patients being bed bound. SIH is secondary to a CSF leak at the level of the spine and the resulting loss of CSF volume to support the brain and spinal cord. Delay in diagnosing this condition may subject patients to unnecessary procedures and prolong morbidity. We describe a 42 years old male patient with SIH and outline the important clinical and radiographic features of this syndrome.
\end{abstract}

Keywords: Low CSF pressure headache; Orthostatic headache; Postural headache; Spontaneous Intracranial hypotension; Spontaneous CSF leak Abbreviations: SIH: Spontaneous Intracranial Hypotension; MRI: Magnetic Resonance Imaging; CSF: Cerebral Spinal Fluid; CT: Computed Tomography

\section{Introduction}

Spontaneous intracranial hypotension is increasingly recognized as an important cause of new daily persistent headaches, although an initial misdiagnosis remains common [1]. Intracranial hypotension may be spontaneous (primary) or related to prior injury (secondary), such as brain or spine trauma. The annual incidence of spontaneous intracranial hypotension is about 5per 100,000 persons [1].

Patients with intracranial hypotension may present with the classic postural headache and a broad spectrum of symptoms including nausea, vomiting, neck pain, visual and hearing disturbances, and vertigo. These various clinical presentations may lead to misdiagnosis of intracranial hypotension, thus delaying effective treatment. SIH is characterized by headache worse on standing, relieved on lying down and is the most common presentation .Careful history taking and a high level of suspicion are essential to diagnosing this syndrome.

Low CSF pressure is a well-known feature of spontaneous intracranial hypotension (SIH) and is one of several diagnostic criteria for the disorder [1,2]. A number of imaging findings have been described including dural enhancement, reversible pituitary enlargement [3,4], subdural collections, brainstem slumping, and caudal tonsillar displacement [3,5-7]. MRI is vital in the diagnosis of intracranial hypotension and ruling out any other conditions. The aim of this study was to demonstrate MRI features of SIH, in a $42 \mathrm{yrs}$ old male who presented with persistent headache for 2 weeks.

\section{Case Report}

A 42 year old man complained of gradual worsening of headache over a period of 2 weeks. The pain was described as a "dragging" sensation, most severe at the occipital region. It worsened on standing up and improved when he was in a recumbent position. He became progressively bedbound, being only able to sit up for short periods before he had to lie down again.

There was no past history of headaches or precursors of migraine. There was no history of convulsion, head trauma, blurring of vision, diplopia, photophobia, decreased hearing, skin rash, tick bites, or fever or chills, vertigo, dizziness, unsteady gait and family history was negative for headaches. Patient took 


\section{Journal of Tumor Medicine \& Prevention}

treatment from a private practitioner for $1-2$ weeks without much relief. His past medical history was unremarkable.

Physical examination revealed no abnormality and lumbar puncture (LP) showed low opening pressure that was unrecordable. Blood pressure was normal without postural hypotension, and he was afebrile. Ear examination showed clear canals with normal tympanic membranes. Neck showed normal range of motion. Ophthalmologic examination showed normal eye movement, equal, round reactive pupils and fundoscopic examination was also normal. His vision was intact.

Neurological examination revealed normal cranial nerves. Muscle Strength, sensations, and coordination were normal
Serum chemistry values, peripheral blood count and differential count, and the erythrocyte sedimentation rate were normal. His Romberg test was negative and there were no signs of cerebellar dysfunction.

Laboratory analysis of CSF fluid showed a cell count of 3/ $\mathrm{mm}^{3}$ (normal, 0 to $4 / \mathrm{mm}^{3}$ ), all lymphocytes, no red blood cells, protein value of $42 \mathrm{mg} / \mathrm{dL}$ (normal, 30 to $45 \mathrm{mg} / \mathrm{dL}$ ), and glucose value of $50 \mathrm{mg} / \mathrm{dL}$ (normal, 45 to $60 \mathrm{mg} / \mathrm{dL}$ ). Corresponding random blood glucose was $100 \mathrm{mg} / \mathrm{dl}$. Results of cultures and cytologic examination were negative. His screening morning serum cortisol was normal $(13 \mathrm{mg} / \mathrm{dL})$. HIV ELISA was nonreactive. Thyroid function test was within normal limits.
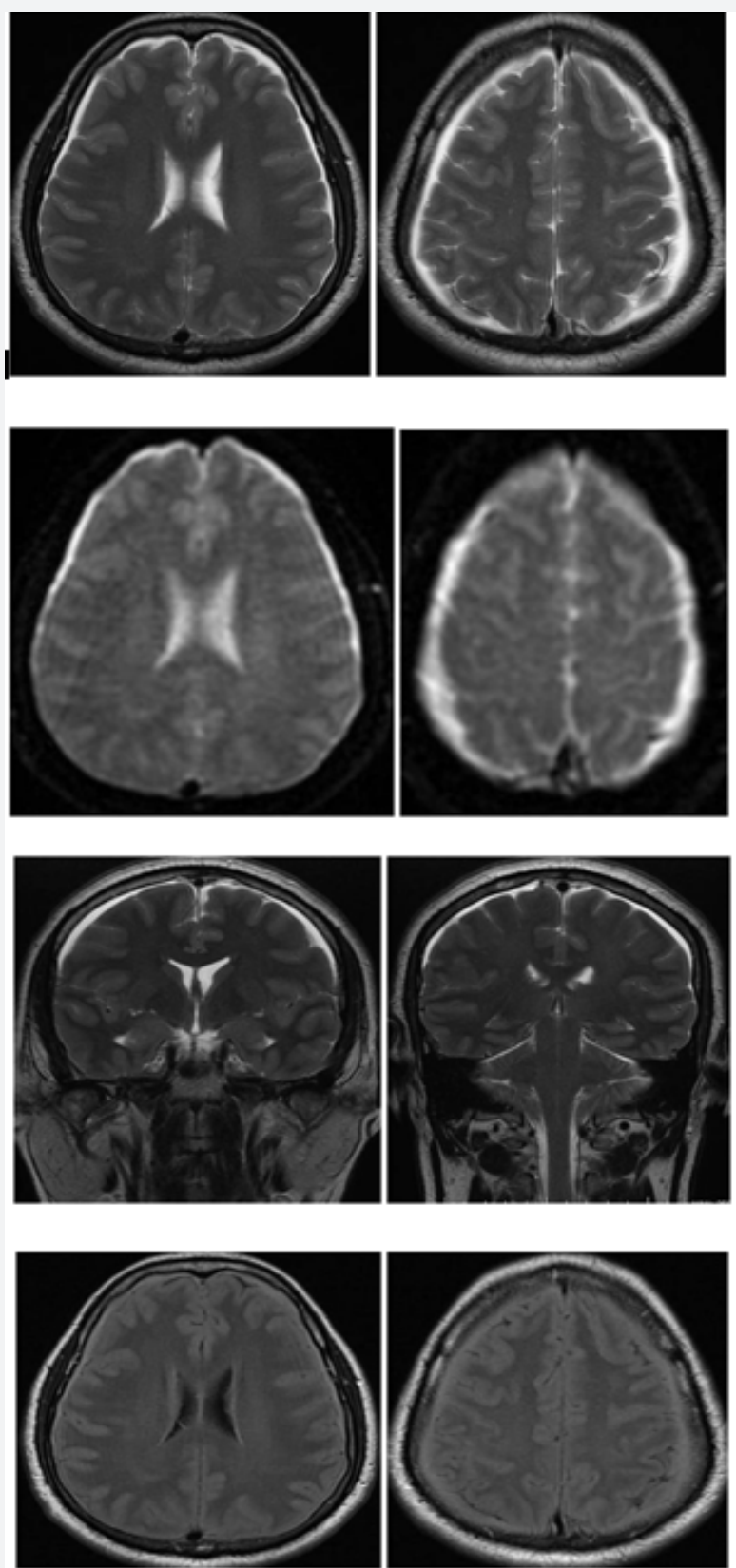

Figure 1: (A-H) 42-year-old man with positional headaches. Axial T2W (A, B), ADC(C, D) \& Coronal T2W (E, F) \& Axial FLAIR (G, H), MR image displays hyperintense subdural collections overlying bilateral cerebral convexities with mild mass effect on subjacent parenchyma. 


\section{Journal of Tumor Medicine \& Prevention}

CT brain study was unremarkable and the patient proceeded to Non contrast \& contrast-enhanced MRI. On T2-weighted images, there were, bilaterally symmetrical small hyper intense fluid collections (Figure 1A-1F), which were located in the cerebral and cerebellar subdural spaces and were also hyper intense on FLAIR images (Figure $1 \mathrm{G} \& 1 \mathrm{H}$ ).
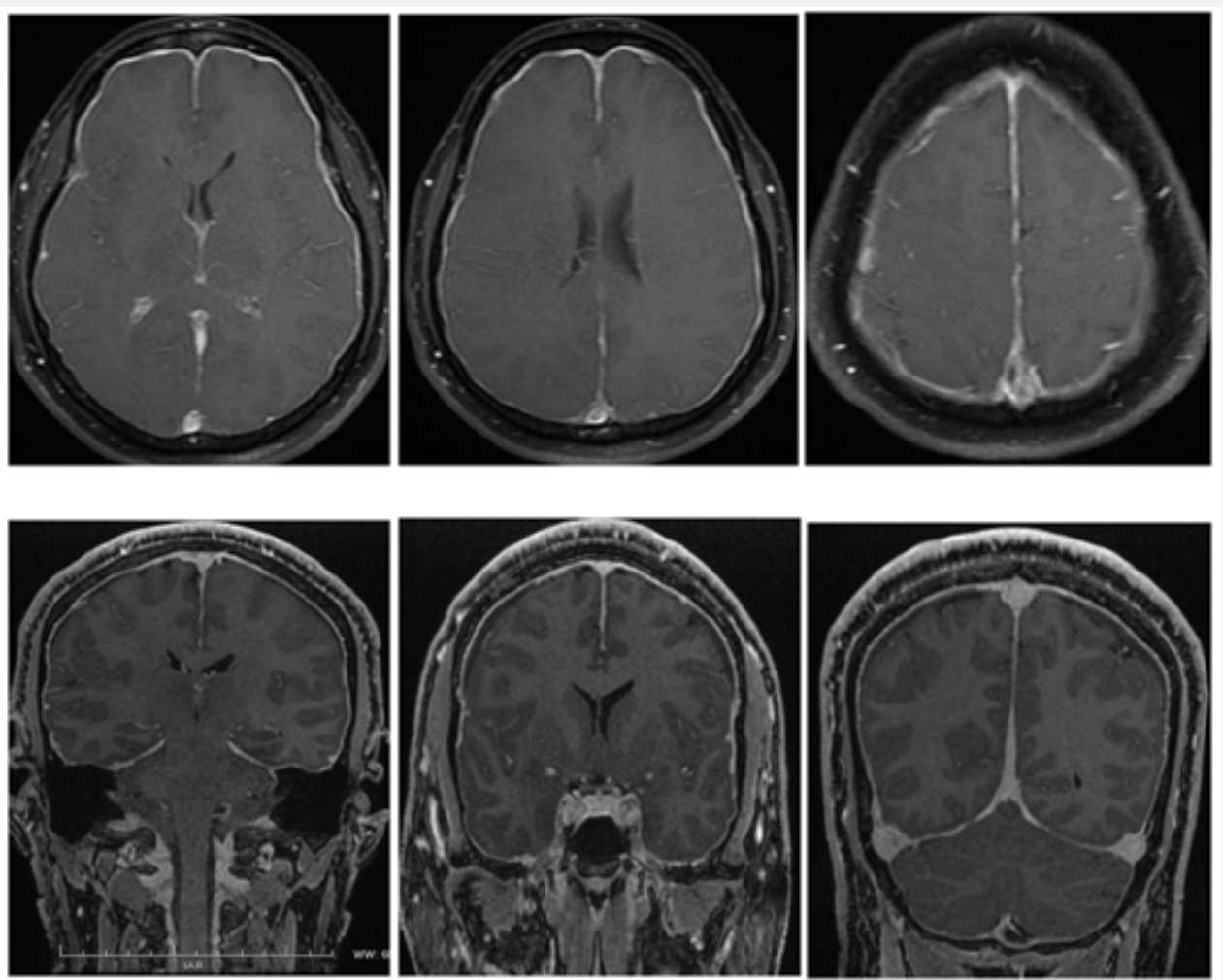

Figure 2: (A-F) 42-year-old man with orthostatic hypotension.MRI gadolinium enhanced Axial (A-C) \& Coronal (D-F) images showing bilateral enhancing subdural fluid collections.
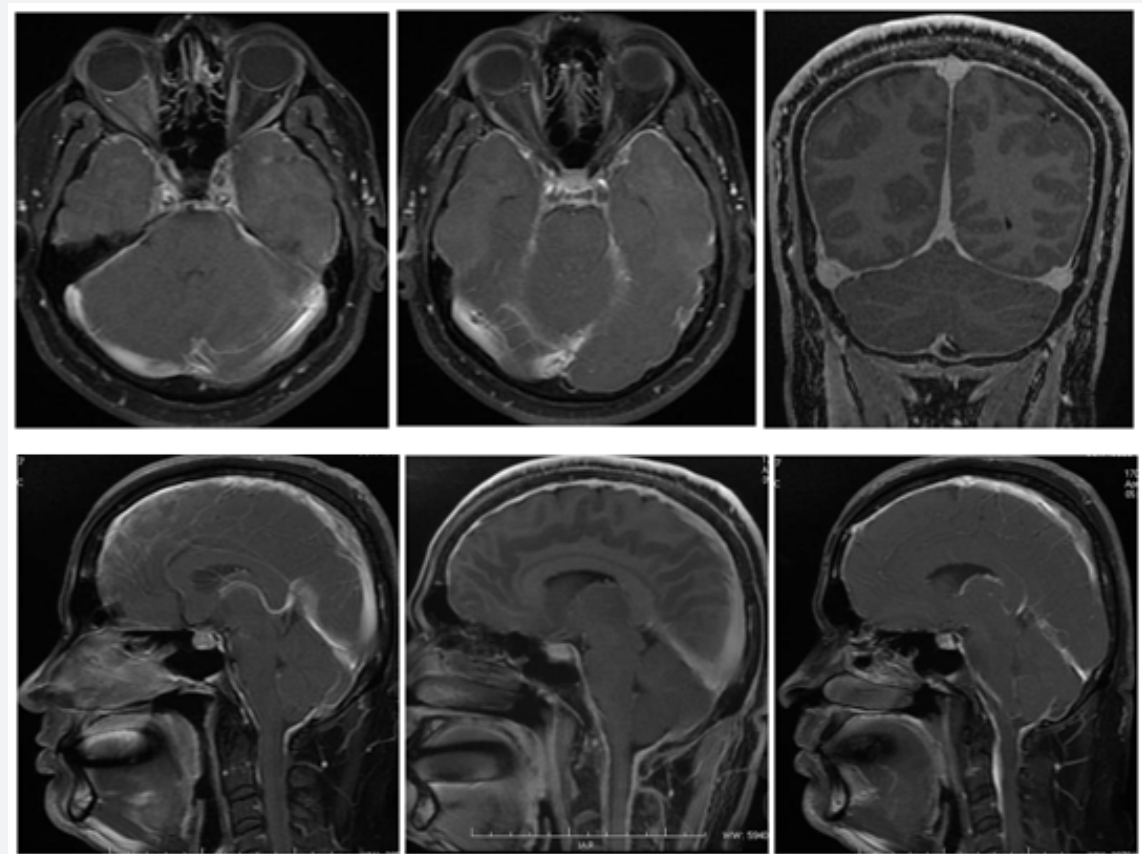

Figure 3: (A-F) 42-year-old man with SIH. MRI gadolinium enhanced Axial (A,B), Coronal (C) and Sagittal (D, F) images showing downward displacement (sagging) of brain, inferiorly displaced cerebellar tonsils and reduction of the -Pre-pontine CSF with round contour of Superior sagittal sinus, Transverse sinus and diffuse pachymeningeal enhancement of Falx \& Tentorium cerebelli. The dural enhancement extends into the spinal canal. 
After contrast media injection, there was diffuse and uniform intense enhancement of all the dural surfaces, including the Falx and tentorium. The thickened and enhancing dura showed a smooth, non-nodular pattern (Figure 2A-2F). In addition, there was venous engorgement of the superior sagittal and transverse sinuses and prominent hyperaemic enhancement of the pituitary gland. The brain was sagging, with inferiorly displaced cerebellar tonsils and decreased pre-pontine CSF space (Figure 3A-3F).

Diagnostic intracranial angles revealed reduced Pontomesencephalic angle of $35^{\circ} \&$ Mamillopontine distance of $4.6 \mathrm{~mm}$, as measured on ADW GE Work station using standard angle-measuring tool (Figure 4A). T2W Coronal image (Figure 4B) at the level of fornices \& 3rd ventricle showed narrowed lateral ventricular angle of $128^{\circ}$.

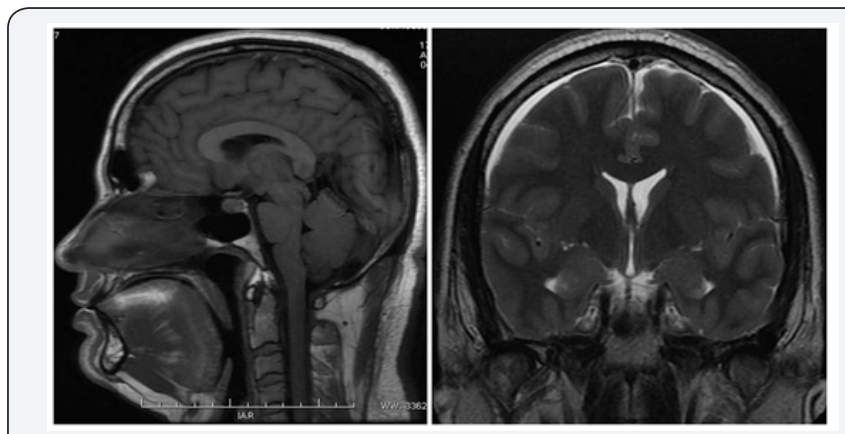

Figure 4: $(\mathrm{A}, \mathrm{B})$ Diagnostic intracranial angles in 42-year-old patient with intracranial hypotension. A. T1W Sagittal image. Ponto mesencephalic angle is narrowed to $35^{\circ}$ \& Mamillo-pontine distance is narrowed to $4.6 \mathrm{~mm}$, as measured on ADW GE Work station using standard angle-measuring tool. Note also low-lying cerebellar tonsils, downward retraction of pituitary infundibulum, and brainstem slumping. B.T2W Coronal image at the level of fornices \& 3rd ventricle show narrowed lateral ventricular angle of $128^{\circ}$.

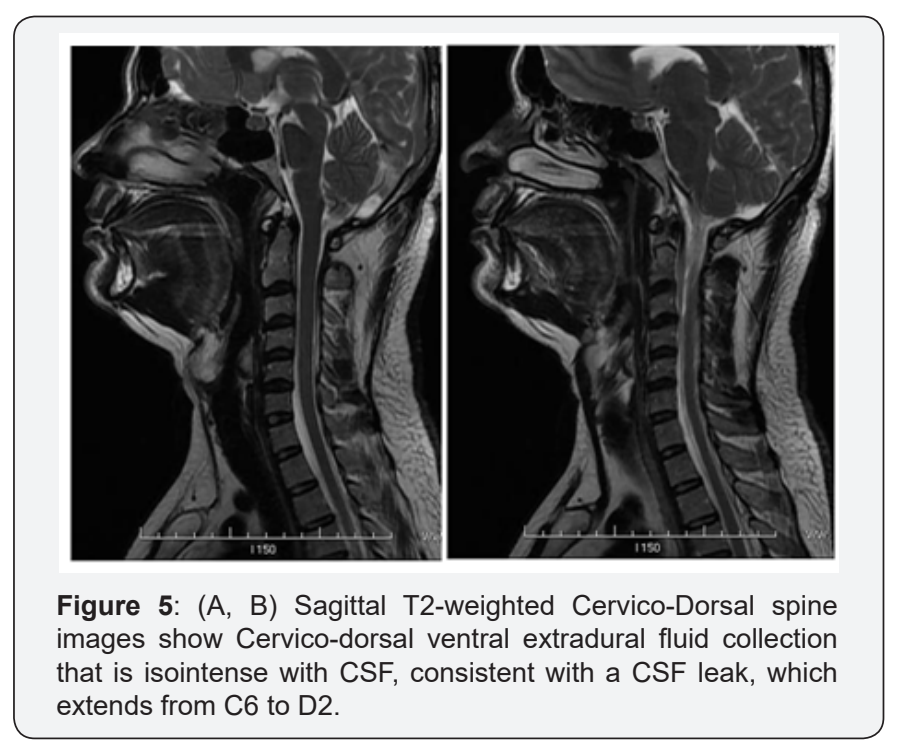

In association with the brain MRI findings, close reexamination of the initial Non contrast spine MRI revealed distension of the cervical epidural veins and epidural fluid collection at the cervico-thoracic junction (Figure 5A \& 5B), consistent with a CSF leak in that region. The diagnosis of SIH was made on the basis of typical headache symptoms, low CSF pressure and characteristic MRI findings.

The patient was put on complete bed rest, and given intravenous normal saline, increased salt intake, oral caffeine. His condition was not improved over the course of 3 days. Hence a trial of therapeutic epidural blood patch has been advocated as the next management step, which involves empirical replacement of lost CSF volume with an autologous blood volume $(10-20 \mathrm{~mL})$ into the epidural space of the spinal canal to tamponade and seal any leaks. At 3-month follow up, the patient reported no headache or systemic symptoms.

\section{Discussion}

SIH was originally described by Schalten brand [8] in 1938 and the MRI findings were later described in 1991 [9]. A constant volume of CSF, approximately $150 \mathrm{ml}$ that is replaced three to four times daily through the choroid plexus system, serves to cushion the brain and spinal cord [10]. SIH results when the loss of CSF due to a dural tear outpaces the ability of the plexus to replace it. The peak incidence of SIH is in the fourth and fifth decades although it also occurs in children and older adults. Women are affected twice as often as men [11].

Orthostatic headache is the prototypical symptom, with occipital or sub-occipital pain occurring or worsening within minutes of assuming the upright position and improvement on resuming recumbency. This classic positional headache is due to downward displacement of the brain due to CSF loss or due to the pain-sensitive dura in the presence of compensatory dilation of venous structures. Not all patients who have SIH have orthostatic headache and not all patients with postural headache have SIH. In some patients, the postural component may be absent or they may have "thunderclap" headache that might result in unnecessary invasive testing for subarachnoid hemorrhage [6].

Other clinical signs and symptoms that have been documented in SIH include nausea, vomiting, diplopia with visual disturbance, cranial nerve palsies and even encephalopathy and coma. Hearing complaints are also very common and are believed to be caused by pressure changes that are transmitted to the cochlea. The sagging brain may also stretch the eighth nerve and other cranial nerves, which is felt to be the mechanism for visual changes such as blurred vision, diplopia, and photophobia [11].

Stretching of the pituitary stalk may cause hyper prolactinemia and galactorrhea [12]. In severe cases of brain descent, deformation may result in ataxia, Parkinsonism, bulbar weakness [13] and cognitive changes [14,15]. Symptoms and signs referable to the spine can occur, including back pain and radiculopathy. Symptoms were attributable to an epidural CSF collection compressing the spinal cord or nerve roots. 
The pathogenesis is usually considered to be an occult CSF leak through small defects in the meninges with a resultant decrease in CSF volume and pressure [16]. The lumbar puncture opening pressure usually is low ranging from $0-70 \mathrm{~mm} \mathrm{H} 20$.

Although exact cause of spontaneous CSF leaks often remains unknown. Two factors are frequently suspected one is -Mechanical factors- including minor trauma or an inciting event like sudden sneezing or sports activity, and the other is an underlying- Connective tissue disorder that may result in dural weakness and play a role in the development of spontaneous low CSF pressure [7]. These include occurrence of meningeal diverticulae and CSF leaks in patients with Marfan's syndrome [17]. Other Connective tissue disorders that may be associated include Ehlers-Danlos syndrome and autosomal dominant polycystic kidney disease [6].

Medical causes of intracranial hypotension (ICH) include dehydration, diabetic coma, hyperpnea, uremia, and severe systemic illness [18]. Most cases of ICH result from a persistent CSF leak, most commonly after dural puncture for a diagnostic lumbar puncture, myelography, or spinal anesthesia. Nonetheless, symptoms of ICH may be experienced any time the dura mater is violated, such as after craniotomy, spinal surgery, cranio-spinal trauma, or placement of a ventriculo-peritoneal shunt [19].

According to the Monroe-Kellie hypothesis, the sum of the volumes of cerebral tissue, intracranial blood and CSF is constant in an intact cranium. Hence, any CSF leak must be compensated by venous engorgement (not arterial as this is tightly auto regulated) or increase in the subdural space [11].

The International classification of Headache disorders requires the following to diagnose a headache due to spontaneous spinal CSF leak: the orthostatic headache as described above along with at least one additional symptom (neck stiffness, tinnitus, hypoacusia, photophobia, or nausea) and confirmatory evidence of low CSF pressure such as on magnetic resonance imaging (MRI) with gadolinium, conventional myelography, computed tomography (CT) myelography, cisternography, or CSF opening pressure [11].

Various imaging techniques help to diagnose SIH and guide treatment. MRI of the brain and spine identify signs of SIH. The common qualitative MRI findings in SIH represent the sum of loss of CSF volume and compensatory changes in response to the leakage. Thin, bilateral, subdural fluid accumulation over the cerebral and cerebellar convexities is commonly seen in about $50 \%$ of patients [20-22]. The pachymeningeal (dural) enhancement is bilateral, diffuse, involves both supratentorial and infratentorial compartments and spares the leptomeninges [7]. This common (in $80 \%$ of cases) and striking appearance has been likened to a "felt tip pen" outlining the thickened, enhancing dura in a diffuse and non-nodular pattern [23]. It is thought to be caused by engorgement of the small, thin-walled dilated blood vessels in the subdural zone [5].
Dural venous sinus engorgement [24,25] and Pituitary hyperaemia or enlargement [26] are also due to compensatory increase in the venous blood component to balance the loss in cranial volume and pressure, but are less constant and less striking signs of SIH. Increased height of the pituitary gland (mean $\pm \mathrm{SD}, 6.9 \pm 2.3 \mathrm{~mm}$ ) has been reported to have a sensitivity of $63 \%$ and specificity of $97 \%$ for the diagnosis of intracranial hypotension [27].

Sagging and downward displacement of the cerebellar tonsils or effacement of prepontine cistern with flattening of the pons against the clivus [7] may mimic a Chiari type1 malformation or it can be misdiagnosed as increased intracranial pressure from space-occupying lesions. Downward drooping of splenium of the corpus callosum (droopy penis sign) and decreased fluid within the optic nerve sheath are the other signs. These qualitative features are not always present, so quantitative findings would be of great help in making more accurate diagnosis based on MRI findings.

The quantitative signs include mamillo-pontine distance $<5.5 \mathrm{~mm}$, ponto-mesencephalic angle $<50^{\circ}$ and callosal angle, also known, as lateral ventricle angle $<130^{\circ}$. In patients with the clinical suspicion of intracranial hypotension, the cutoff values of $5.5 \mathrm{~mm}$ or less for the mamillopontine distance and $50^{\circ}$ or less for the pontomesencephalic angle were sensitive and specific in strengthening the qualitative MRI findings. Therefore, quantitative assessments may provide a more accurate diagnosis [26].

The mamillo-pontine distance is defined as the distance between the inferior aspect of the mamillary bodies and the superior aspect of the pons. This measurement approximates the interpeduncular cistern. The ponto-mesencephalic angle is defined as the angle between a line tangential to the anterior margin of the midbrain and the line tangential to the superior margin of the pons. The lateral ventricular angle is delineated as the angle between the medial margins of the right and left lateral ventricles. This angle was measured on coronal images at the level of the fornices, third ventricle, and pituitary infundibulum [28].

Venous engorgement is defined as prominent dural venous sinus enhancement with enlarged and rounded sinuses [4]. On sagittal T1-weighted MRI, the convex bulging of the inferior border of the dominant transverse sinus seen in intracranial hypotension patients has been described as the "venous distention" sign [29]. Brainstem slumping is defined as a lowlying third ventricle at or below the level of the floor of the sella turcica, horizontal configuration of the infundibulum, and red nuclei below the level of the tentorium [30].

Several imaging features of brainstem slumping have been identified and described in the literature including ventricular effacement [7], effacement of the suprasellar and prepontine cisterns, bowing of the optic chiasm over the sella turcica, 
flattening of the central pons [30], and caudal displacement of the cerebellar tonsils $[1,4,11]$.

The differential diagnosis of the MRI findings in SIH is important and includes idiopathic hypertrophic pachymenigitis which can present with diffuse dural enhancement. Metastatic malignant tumor deposits cause multifocal and nodular pachymeningeal enhancement rather than diffuse [31]. Infectious meningitis typically affects the leptomeninges rather than pachymeninges. However tuberculosis can cause pachymeningitis as well as leptomeningitis [32].

CT myelography (CTM) and intrathecal gadolinium magnetic resonance myelography (Gd-MRM), localize spinal CSF leaks. Standard CTM is best to localize suspected slow leaks, which remain confined over at most two vertebral levels between the time of fluoroscopically guided contrast instillation and CT acquisition [33]. Dynamic CTM is best to localize suspected fast leaks, which would otherwise spread over many levels, obscuring the actual leakage site [33]. Gd-MRM has higher sensitivity than CTM for small, slow leaks, but is more complex to perform [32,33]. CTM and Gd-MRM both have higher sensitivity and spatial resolution than radionuclide cisternography [34,35]. Despite their increased sensitivity, CTM and Gd-MRM fail to identify a CSF leak in close to half of subjects with suspected SIH $[33,34]$.

Many patients respond to conservative measures alone, including bed rest, oral hydration, oral caffeine, and an abdominal binder. Other supportive measures included are oral corticosteroids, intravenous caffeine, and theophylline, but their effectiveness has been limited [36].

Lumbar epidural blood patch (LEBP) is the time-honored approach for the treatment of post dural puncture headache when conservative treatment fails [37]. Many patients with intracranial hypotension experience symptom relief within minutes after the LEBP [38,39]. Sustained relief presumably occurs due to tamponade and then sealing of the dural defect by the LEBP, followed by gradual restoration of CSF volume [38]. Indeed, targeted cervico-thoracic Epidural blood patching (EBP) has succeeded in cases when LEBP has failed [40]. In some cases where EBP has failed, epidural fibrin glue patching has succeeded when used alone [41] or mixed with autologous blood [42].

Surgery is sometimes effective for the small minority of patients who remain refractory to conservative measures, one or more EBPs, and possibly one or more epidural fibrin glue patching $[43,44]$. Our patient underwent EBP \& reported no headache or systemic symptoms at the end of 3-months follow up.

\section{Conclusion}

$\mathrm{SIH}$ is a rare syndrome that should be considered in the differential diagnosis of daily persistent headache. Spontaneous CSF leakage from the spinal canal can give rise to SIH. Typically, these patients complain of orthostatic (postural) headache, have very low CSF pressure on lumbar puncture and usually respond to conservative treatment or by an epidural blood patch. The characteristic MRI features include subdural fluid collections, enhancement of the pachymeninges and engorgement of venous structures, pituitary hyperaemia and sagging of the cerebellar tonsils. Knowledge of the typical MRI features \& clinical findings can help radiologists confidently diagnose the rare but characteristic syndrome of SIH, and avoid unnecessary investigations and surgical procedures.

\section{References}

1. Schievink WI (2003) Misdiagnosis of spontaneous intracranial hypotension. Arch Neurol 60(12): 1713-1718.

2. Headache Classification Committee of the International Headache Society (IHS) (2013) The International Classification of Headache Disorders. Cephalalgia 33(9): 629-808.

3. Dillon WP, Fishman RA (1998) Some lessons learned about the diagnosis and treatment of spontaneous intracranial hypotension. AJNR 19(6): 1001-1002.

4. Yuh EL, Dillon WP (2010) Intracranial hypotension and intracranial hypertension. Neuroimaging Clin N Am 20(4): 597-617.

5. Mokri B, Piepgras DG, Miller GM (1997) Syndrome of orthostatic headaches and diffuse pachymeningeal gadolinium enhancement. Mayo Clin Proc 72(5): 400-413.

6. Schievink WI, Meyer FB, Atkinson JL, Mokri B (1996) Spontaneous spinal cerebrospinal fluid leaks and intracranial hypotension. J Neurosurg 84(4): 598-605.

7. Fishman RA, Dillon WP (1993) Dural enhancement and cerebral displacement secondary to intracranial hypotension. Neurology 43(3): 609-611.

8. Schaltenbrand G (1938) Neuere Anschauungen zur Pathophysiologie derliquorzirkulation. Zentralbl Neurochir 3: 290-300.

9. Mokri B, Krueger BR, Miller GM, David G Piepgras (1993) Meningeal gadolinium enhancement in low pressure headaches. J Neuroimaging 3(1): 11-15.

10. Patel PM, Drummond JC (2010) Cerebral physiology and the effects of anesthetic drugs. Miller's Anesthesia Edited by Miller RD (ed.), Churchill Livingstone, Philadelphia, USA 7: 322.

11. Schievink WI (2006) Spontaneous spinal cerebrospinal fluid leaks and intracranial hypotension. JAMA 295(19): 2286-2296.

12. Yamamoto M, Suehiro T, Nakata H, Nishioka T, Itoh H, et al. (1993) Primary low cerebrospinal fluid pressure syndrome associated with galactorrhea. Intern Med 32(3): 228-231.

13. Pakiam AS, Lee C, Lang AE (1999) Intracranial hypotension with parkinsonism, ataxia, and bulbar weakness. Arch Neurol 56(7): 869872.

14. Wicklund MR, Mokri B, Drubach DA, Boeve BF, Parisi JE (2011) Frontotemporal brain sagging syndrome: An SIH-like presentation mimicking FTD. Neurology 2011 76: 1377-1382.

15. Ghavanini AA, Scott CA, Chan DK, Tang-Wai DF (2013) Management of patients with spontaneous intracranial hypotension causing altered level of consciousness: Report of two cases and review of literature. Cephalalgia 33(1): 43-51.

16. Rando T, Fishman R (1992) Spontaneous intracranial hypotension: report or two cases and review of the literature. Neurol 42(3): 481448. 
17. Davenport RJ, Chataway SJ, Warlow CP (1995) Spontaneous intracranial hypotension from a CSF leak in a patient with Marfan's syndrome. J Neurol Neurosurg Psychiatry 59(5): 516-519.

18. Bruera O, Bonamico L, Giglio JA (2000) Intracranial hypotension: the nonspecific nature of MRI findings. Headache 40(10): 848-852.

19. Marcelis J, Silberstein SD (1990) Spontaneous low cerebrospinal fluid pressure headache. Headache 30(4): 192-196.

20. Holmes JM (1953) Intracranial hypotension associated with subdural haematoma. BMJ 20(1): 1363-1366.

21. Sipe JC, Zyroff J, Waltz TA (1981) Primary intracranial hypotension and bilateral isodense subdural hematomas. Neurology 31(3): 334-337.

22. Pannullo SC, Reich JB, Krol G (1993) MRI changes in intracranial hypotension. Neurology 43(5): 919-926.

23. Schoffer KL, Benstead TJ, Grant I (2002) Spontaneous intracranial hypotension in the absence of magnetic resonance imaging abnormalities. Can J Neurol Sci 29(3): 253-257.

24. Koss SA, Ulmer JL, Hacein-Bey L (2003) Angiographic features of spontaneous intracranial hypotension. AJNR Am J Neuroradiol 24(4): 704-706.

25. Roll JD, Larson TC, Soriano MM (2003) Cerebral angiographic findings of spontaneous intracranial hypotension. AJNR Am J Neuroradiol 24(4): 707-708.

26. Mamelak AN, Fishman RA, Dillon WP (1996) Spontaneous intracranial hypotension. J Neurosurg 85(1): 192-193.

27. Lubdha M, Logan A, McLean, Heilbrun ME (2013) Salzman Intracranial Hypotension: Improved MRI Detection with Diagnostic Intracranial Angles. AJR 200(2): 400-407.

28. Rohr A, Jensen U, Riedel C, van Baalen A, Fruehauf MC, et al. (2010) MR imaging of the optic nerve sheath in patients with craniospinal hypotension. AJNR 31(9): 1752-1757.

29. Nayak L, Abrey LE, Iwamoto FM (2009) Intracranial dural metastasis. Cancer 115(9): 1947-1953.

30. Farb RI, Forghani R, Lee SK, Mikulis DJ, Agid R (2007) The venous distension sign: a diagnostic sign of intracranial hypotension at MR imaging of the brain. AJNR 28(8): 1489-1493.

31. Savoiardo M, Minati L, Farina L, De Simone T, Aquino D, et al. (2007) Spontaneous intracranial hypotension with deep brain swelling. Brain 130(Pt 7): 1884-1893.

32. Goyal M, Scharma A, Mishra NK, Gaikwad SB, Sharma MC (1997) Imaging apparearance of parechymeningeal tuberculosis. AJR Am J Roentgenol 169(5): 1421-1424.

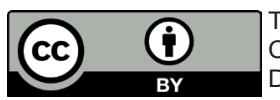

This work is licensed under Creative Commons Attribution 4.0 Licens DOI: 10.19080/JTMP.2017.01.555564
33. Luetmer PH, Schwartz KM, Eckel LJ, Hunt CH, Carter RE, et al. (2012) When should I do dynamic CT myelography? Predicting fast spinal CSF leaks in patients with spontaneous intracranial hypotension. AJNR Am J Neuroradiol 33(4): 690-694.

34. Akbar JJ, Luetmer PH, Schwartz KM, Hunt CH, Diehn FE, et al. (2012) The role of MR myelography with intrathecal gadolinium in localization of spinal CSF leaks in patients with spontaneous intracranial hypotension. AJNR Am J Neuroradiol 33(3): 535-540.

35. Albes G, Weng H, Horvath D, Musahl C, Bäzner H, et al. (2012) Detection and treatment of spinal CSF leaks in idiopathic intracranial hypotension. Neuroradiology 54(12): 1367-1373.

36. Hashizume K, Watanabe K, Kawaguchi M, Taoka T, Shinkai T, et al. (2012) Comparison of computed tomography myelography and radioisotope cisternography to detect cerebrospinal fluid leakage in spontaneous intracranial hypotension. Spine 37(4): E237-E242.

37. Gormley JB (1960) Treatment of postspinal headache. Anesthesiology 21: $565-266$.

38. Kroin JS, Nagalla SK, Buvanendran A, McCarthy RJ, Tuman KJ, et al. (2002) The mechanisms of intracranial pressure modulation by epidural blood and other injectates in a postdural puncture rat model. Anesth Analg 95(2): 423-429.

39. Zada G, Pezeshkian P, Giannotta S (2007) Spontaneous intracranial hypotension and immediate improvement following epidural blood patch placement demonstrated by intracranial pressure monitoring. Case report. J Neurosurg 106(6): 1089-1890.

40. Sencakova D, Mokri B, McClelland RL (2001) The efficacy of epidural blood patch in spontaneous CSF leaks. Neurology 57(10): 1921-1923.

41. Schievink WI, Maya MM, Moser FM (2004) Treatment of spontaneous intracranial hypotension with percutaneous placement of a fibrin sealant. Report of four cases. J Neurosurg 100(6): 1098-1100.

42. Savoiardo M, De Simone T, Franzini A, Broggi G, Chiapparini L (2006) Spontaneous CSF leak treated with percutaneous CT-guided fibrin glue. Neurology 66(5): 782.

43. Cohen-Gadol AA, Mokri B, Piepgras DG, Meyer FB, Atkinson JL (2006) Surgical anatomy of dural defects in spontaneous spinal cerebrospinal fluid leaks. Neurosurgery 58(4): ONS-238-ONS-245.

44. Schievink WI, Morreale VM, Atkinson JL, Meyer FB, Piepgras DG, et al. (1998) Surgical treatment of spontaneous spinal cerebrospinal fluid leaks. J Neurosurg 88(2): 243-246.

Your next submission with Juniper Publishers will reach you the below assets

- Quality Editorial service

- Swift Peer Review

- Reprints availability

- E-prints Service

- Manuscript Podcast for convenient understanding

- Global attainment for your research

- Manuscript accessibility in different formats

( Pdf, E-pub, Full Text, Audio)

- Unceasing customer service

Track the below URL for one-step submission

https://juniperpublishers.com/online-submission.php 